\title{
PENINGKATAN KUALITAS KOMPOSIT SERAT LIMBAH PEMINTALAN KAPAS MELALUI PROSES PENGEPRESAN MENGGUNAKAN PROTOTIPE MESIN KEMPA PANAS (HOT PRESS)
}

\author{
COMPOSITE QUALITY IMPROVEMENT OF COTTON SPINNING WASTE \\ THROUGH PRESSING PROCESS USING HOT PRESS MACHINE PROTOTYPE
}

\author{
Mukti Widodo, Tony Setiawan, Sudaryono, Saeful Islam \\ Balai Besar Tekstil, Jalan Jenderal Ahmad Yani No. 390 Bandung \\ E-mail: texirdti@bdg.centrin.net.id
}

Tanggal diterima: 29 November 2018, direvisi: 5 Juli 2019, disetujui terbit: 12 Juli 2019

\begin{abstract}
ABSTRAK
Penelitian ini dilakukan dengan rancang bangun dan perekayasaan prototipe mesin kempa panas (hot press) yang dapat menghasilkan lembaran komposit. Adapun tujuan dari kegiatan ini, adalah mendapatkan teknologi tepat guna untuk meningkatkan sifat mekanik dari komposit. Mesin kempa panas hasil rekayasa dilakukan kalibrasi temperatur pada 7 (tujuh) tingkat temperatur dengan 5 (lima) titik lokasi pada masing-masing pelat pemanas. Sedangkan eksperimen lapangan melalui pembuatan komposit dengan komposisi: 80\% serat limbah pemintalan kapas dan $20 \%$ low melt. Percobaan dalam pembuatan komposit ini melalui proses pres-panas pada bahan baku berbentuk lembaran nirtenun (nonwoven) dengan ukuran $30 \mathrm{~cm} \times 30 \mathrm{~cm}$. Hasil percobaan terhadap mesin kempa panas hasil rekayasa tersebut menunjukkan mesin tersebut dapat digunakan dengan maksimal sampai dengan temperatur $200^{\circ} \mathrm{C}$ dengan gaya tekan 12 ton. Hasil percobaan dan pengujian terhadap komposit yang diproses melalui mesin kempa panas pada temperatur $140^{\circ} \mathrm{C}$, tekanan $=100$ bar, dan waktu $=20$ detik. Sifat mekanik dari komposit yang dihasilkan sebelum diproses, kekuatan tarik rata-rata sebesar 21,54 kgf, kemuluran rata-rata sebesar $12,23 \mathrm{~mm}$, dan setelah diproses kekuatan tarik rata-rata menjadi 41,62 kgf, kemuluran rata-rata menjadi 18,03 mm. Melalui proses pengepresan dan pemanasan ini didapatkan kenaikan kekuatan tarik sebesar 93,23\% dan kemuluran sebesar 47,40\%. Dengan melihat hasil penelitian ini diharapkan dapat diperoleh peningkatan kualitas mekanik dari proses pembuatan komposit berbahan dasar limbah pemintalan serat kapas melalui kombinasi temperatur dan tekanan dengan menggunakan mesin kempa panas ini.
\end{abstract}

Kata kunci : Low melt, komposit, non woven, hot press

\begin{abstract}
This research was carried out by designing and engineering a hot press machine prototype that can produce composite sheets. The purpose of this activity is obtaining appropriate technology to improve the mechanical properties of composites. The hot press machine was calibrated at 7 (seven) temperature levels with 5 (five) location points on each heating plate. While field experiments through the manufacture of composites with a composition: $80 \%$ cotton spinning waste and $20 \%$ low melt. Experiments in making of these composites are through the process of heat-pressing on material in the form of nonwoven sheet with size of $30 \mathrm{~cm} x 30 \mathrm{~cm}$. The experimental results of the engineered hot press machine showed that the machine could be used maximum up to temperatures of $200^{\circ} \mathrm{C}$ with a compressive force of 12 tons. Experimental results and testing of composites were processed through a hot press machine at a temperature of $140^{\circ} \mathrm{C}$, pressure $=100 \mathrm{bar}$, and time $=20$ seconds. The mechanical properties of the composites produced before processing, the average tensile strength of $21.54 \mathrm{kgf}$, the average elongation of $12.23 \mathrm{~mm}$, and after processing the average tensile strength of $41.62 \mathrm{kgf}$, the average elongation of $18.03 \mathrm{~mm}$. Through this pressing and heating process, an increase in tensile strength of $93.23 \%$ and elongation of $47.40 \%$ were obtained. By looking at the results of this study it is expected to be able to obtain a mechanical quality improvement from the composite manufacturing process based on cotton fiber spinning waste through a combination of temperature and pressure using this hot press machine.
\end{abstract}

Keywords : Low melt, composite, non woven, hot press 


\section{PENDAHULUAN}

Tanaman kapas banyak ditemukan di berbagai benua yaitu Asia, Afrika, Australia, dan Amerika. Tanaman kapas telah lama dikenal dan dibudidayakan sejak zaman prasejarah. Awalnya kapas digunakan terbatas untuk kebutuhan rumah tangga sampai ditemukan mesin pemisah biji kapas. Sejak itu kapas ditanam terutama untuk diambil serat bijinya bagi industri tekstil. ${ }^{1,2}$ Serat kapas merupakan serat alami dengan ciri-ciri sel memanjang yang datar, bengkok, berongga, dan struktur seperti pita terdiri dari zat penyusun antara lain: selulosa, pektat atau pectin, protein, lilin, debu, dan zat lain. ${ }^{3}$ Serat kapas banyak digunakan sebagai bahan baku tekstil, yang dimulai dari pembuatan benang kapas atau proses pemintalan kapas. Pada proses pemintalan kapas akan selalu dihasilkan limbah atau waste, baik yang berasal bahan baku kapas maupun proses pemintalan tersebut. Limbah merupakan non product output dari kegiatan industri tekstil. Khusus industri tekstil yang di dalam proses produksinya mempunyai unit pemintalan mempunyai potensi sebagai penyebab pencemaran limbah padat berupa limbah benang, limbah serat, debu, dan zat lainnya. Pada umumnya limbah padat yang dihasilkan pada industri pemintalan kapas sekitar 15 - 30 persen dari material yang digunakan. Studi yang dilakukan oleh Balai Besar Tekstil (BBT) pada tahun 2016 di suatu industri pemintalan kapas, dari penggunaan material kapas 18 ton/hari akan dihasilkan limbah sebesar 1 ton/hari atau sekitar 5 persen yang tidak bisa digunakan kembali (reuse) pada proses pemintalan. Dari total limbah tersebut, sekitar $80 \%$ masih mengandung serat dan sisanya $20 \%$ berupa kotoran, debu, tanah dan lain sebagainya.

Salah satu potensi pemanfaatan limbah pemintalan serat kapas adalah dengan menjadikannya bahan baku dalam pembuatan komposit. Komposit merupakan kombinasi dari dua bahan atau lebih yang tersusun dari matriks dan penguat (yang dipilih berdasarkan kombinasi sifat mekanik dan fisik masing-masing material penyusun) untuk menghasilkan material baru dengan sifat yang unik dibandingkan sifat material dasar sebelum dicampur dan terjadi ikatan permukaan antara masing-masing material penyusun. Dengan adanya perbedaan sifat material penyusun di mana antar material harus terjadi ikatan yang kuat maka wetting agent kadang perlu ditambahkan. Dengan nilai kekuatan yang lebih tinggi dan keunggulan lain seperti ringan dan tahan korosi menyebabkan material komposit menjadi pilihan utama dalam pengembangan produk ${ }^{4}$. Kekuatan material komposit telah dapat mencapai di atas $1000 \mathrm{MPa}$ dan melebihi kekuatan beberapa material dari bahan logam. ${ }^{5}$
Matriks dan serat (fiber) adalah bahan pembentuk material komposit di mana serat sangat berperan dalam memberikan kekuatan dan kekakuan komposit. Namun aspek lain yang menjadi sumber kekuatan komposit didapat dari matriks yang memberikan ketahanan terhadap temperatur tinggi, ketahanan terhadap tegangan geser dan mampu mendistribusikan beban. Matriks memberikan pengaruh yang lebih besar dalam pengikatan material penyusun selain bertugas untuk mendistribusikan beban dan memberikan perlindungan dari pengaruh lingkungan. Polyester dan vinyl ester resin umumnya yang paling banyak digunakan sebagai bahan matriks dan biasanya digunakan untuk pembuatan produk-produk komersial, industri dan transportasi. Namun bila produk yang dibutuhkan diharapkan untuk memiliki kekuatan yang lebih tinggi maka bahan epoksi menjadi pilihan sebagai matriks. Meskipun epoksi sensitif terhadap kelembaban, namun tetap masih lebih baik dibanding dengan polyester serta tahan terhadap penyusutan. Dalam aplikasinya epoksi terbatas terhadap termperatur hingga $120^{\circ} \mathrm{C}$ untuk pemakaian jangka panjang, bahkan pada kondisi tertentu temperatur tertinggi hanya pada sekitar $80^{\circ} \mathrm{C}$ sampai $105^{\circ} \mathrm{C}$. Untuk pemakaian pada temperatur lebih tinggi sekitar $177^{\circ} \mathrm{C}$ sampai $230^{\circ} \mathrm{C}$ dapat menggunakan bismaleimide resins (BMI) sebagai matrik. ${ }^{6}$

Ditinjau dari penggunaan matriks, komposit yang cukup banyak digunakan saat ini adalah komposit bermatriks polimer. Hal ini karena polimer memiliki proses manufaktur yang relatif sederhana, sifat mekanik yang baik, dan membentuk ikatan yang baik dengan sebagian besar penguat ${ }^{8}$. Serat polyester low melt merupakan salah satu polimer yang dapat digunakan sebagai matriks. Material ini memiliki karakteristik di antaranya: dapat meleleh pada temperature rendah $\left(110-200^{\circ} \mathrm{C}\right)$, membentuk ikatan dengan baik, daya tahan yang tinggi, dan mudah dicampur dengan serat lain. ${ }^{19}$

\section{METODE}

\section{Bahan dan Peralatan Penelitian}

Bahan-bahan untuk perekayasaan mesin kempa panas (hot press) digunakan untuk membuat bagian-bagian dari mesin ini. Untuk pembuatan bagian rangka atau frame menggunakan bahan-bahan antara lain besi kanal 10 , besi siku 4, besi strip, cat, dan thinner. Sedangkan pembuatan bagian penekan dan pemanas menggunakan besi pelat, hidrolik dengan kapasitas 15 ton dan elemen pemanas 4 x 600 watt. Bagian pemanas dilengkapi oleh pengendali daya dan temperatur yang komponen-komponennya antara lain: miniature circuit breaker (mcb), contactor, dan temperature controller. 
Mesin-mesin perkakas yang digunakan dalam pembuatan mesin kempa panas ini juga memerlukan bahan-bahan atau komponenkomponen habis pakai antara lain batu gerinda potong, elektroda, dan pahat bubut. Sedangkan untuk uji coba mesin kempa panas ini digunakan bahan berupa lembaran nirtenun yang terbuat dari serat limbah pemintalan serat kapas dan sebagai matriks digunakan polyester low melt dengan perbandingan $4: 1$.

Peralatan (software dan hardware) yang digunakan dalam penelitian ini antara lain :

- Software Autocad

- Mesin bubut dengan kemampuan membuat ulir metrik

- Mesin las dengan elektroda 2.6.

- Mesin gerinda potong.

- Mesin gerinda pahat.

- Mesin milling universal.

- Mesin potong pelat.

- Multimeter

- Kunci-kunci aneka ukuran, obeng, palu, dan peralatan kerja bangku lainnya.

\section{Desain Mekanisme Pengepresan pada Mesin Kempa Panas}

Desain mekanisme pengepresan mesin ini dirancang dengan memperhitungkan tekanan pengepresan yang akan digunakan pada pembentukan komposit termoplastik agar didapatkan sifat mekanik komposit yang diinginkan. Untuk proses pengepresan ini digunakan komponen pengepres yang dapat memberikan gaya tekan pada lembaran komposit, yaitu sistem hidrolik. Sistem hidrolik yang dipilih menggunakan media penghantar berupa fluida cair (oli). Fluida penghantar ini dinaikkan tekanannya oleh pompa pembangkit tekanan yang kemudian diteruskan ke silinder kerja melalui pipa-pipa saluran dan katup-katub. Kerja yang diakibatkan oleh tekanan fluida pada ruang silinder dimanfaatkan untuk gerak maju dan mundur. Prinsip dasar sistem hidrolik berasal dari Hukum Pascal, dimana tekanan dalam fluida statis mempunyai sifat-sifat sebagai berikut:

1. Tekanan bekerja tegak lurus pada permukaan bidang.

2. Tekanan di setiap titik sama untuk semua arah.

3. Tekanan yang diberikan ke sebagian fluida dalam tempat tertutup, merambat secara seragam ke bagian lain fluida.

Prinsip desain mekanisme pengepresan pada penelitian ini menggunakan sistem hidrolik yang dapat dilihat pada Gambar 1, di mana dua buah silinder berisi oli yang dihubungkan dan mempunyai diameter berbeda. Apabila gaya $F_{1}$ diberikan pada silinder kecil, tekanan $\mathrm{P}$ yang dihasilkan akan diteruskan ke silinder besar ( $\mathrm{P}=$ $\mathrm{F}_{1} / \mathrm{A}_{1}$, gaya dibagi luas penampang silinder).
Menurut hukum ini, penambahan gaya sebanding dengan luas rasio penampang silinder besar dan silinder kecil, atau $\mathrm{F}_{2}=\mathrm{P} \times \mathrm{A}_{2}=\mathrm{F}_{1} \times \mathrm{A}_{2} / \mathrm{A}_{1 .}{ }^{10}$

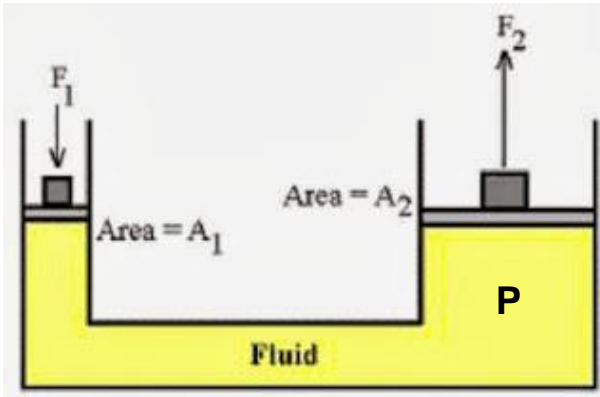

Gambar 1. Mekanisme kerja hidrolik

Pada penelitian ini, tekanan minimal pengepresan yang dibutuhkan pada lembaran nonwoven sebesar $P=5 \mathrm{~kg} / \mathrm{cm}^{2}$. Sedangkan luas penampang pelat penekan sebesar $\mathrm{A}=30 \mathrm{~cm} \times 30$ $\mathrm{cm}=900 \mathrm{~cm}^{2}$. Maka kapasitas minimal perangkat hidrolik yang dibutuhkan sebesar $\mathrm{F}=\mathrm{P} \times \mathrm{A}=5$ $\mathrm{kg} / \mathrm{cm}^{2} \times 30 \mathrm{~cm} \times 30 \mathrm{~cm}=4.500 \mathrm{~kg}=4,5$ ton.

Pada perekayasasaan mesin ini, fluida oli dirancang dan dioperasikan agar dapat mengalir dengan mudah melalui komponen-komponen salurannya dengan sedikit hambatan aliran untuk mengurangi tenaga yang hilang. Fluida oli juga sedapat mungkin dikondisikan mempunyai sifat tidak kompresibel yaitu dengan meminimalkan tercampur dengan udara sehingga gerakan yang terjadi pada saat pompa digerakkan atau katup dibuka dengan segera oli dapat dipindahkan. ${ }^{10,11}$

\section{Desain Mekanisme Pemanasan pada Mesin Kempa Panas}

Perekayasaan mesin kempa panas ini salah satunya bertujuan untuk membuat mesin yang dapat memberikan variasi temperatur pada material komposit limbah serat kapas dan polyester low melt agar diketahui pengaruhnya terhadap sifat mekanik (kekuatan tarik, kekuatan bending, dan impak). ${ }^{11-13}$

Pada penelitian ini lembaran komposit akan dipanaskan menggunakan sumber energi listrik. Metoda penggunaan energi listrik sebagai sumber panas melalui prinsip Joule (Joule Heating) yaitu dengan cara konversi energi listrik menjadi energi panas dan alat yang digunakan yaitu elemen pemanas. Prinsip kerja elemen panas adalah arus listrik yang mengalir pada elemen menjumpai resistansinya, sehingga menghasilkan panas pada elemen. Jika pemanas dimodelkan sebagai suatu beban resistif, maka besarnya kalor per unit waktu sesuai dengan persamaan:

$$
\mathrm{P}=\frac{V^{2}}{R}
$$


Dengan $\mathrm{P}$ adalah daya elemen pemanas (watt), $\mathrm{V}$ adalah tegangan efektif (volt) yang diberikan di elemen pemanas, dan $\mathrm{R}$ adalah resistansi elemen pemanas (ohm). ${ }^{15,16}$

Pada perekayasaan mesin kempa panas ini digunakan dua buah elemen pemanas pada masingmasing pelat pemanas (atas dan bawah). Setiap elemen pemanas memiliki daya $\mathrm{P}$ sebesar 600 watt. Dengan tegangan sumber listrik $\mathrm{V}$ sebesar $220 \mathrm{~V}$, maka tahanan yang bekerja pada elemen ini sebesar $\mathrm{R}=\mathrm{V}^{2} / \mathrm{P}=(220)^{2} / 600=80,67 \mathrm{ohm}$.

\section{Desain Mekanisasi Mesin Kempa Panas}

Desain mekanisasi mesin kempa panas ini di samping mempertimbangkan fungsi pengepresan dan pemanasan, juga mempertimbangkan kemudahan dalam pengoperasian. Mesin ini juga mudah untuk dipindahkan karena dilengkapi empat buah roda pada kaki-kakinya. Mesin kempa panas ini dirancang sebagai mesin skala laboratorium yang akan digunakan untuk membuat sampel komposit. Desain mekanisasi mesin kempa panas ini secara umum terdiri dari sistem rangka atau frame dan sistem pelat kempa panas. Desain mesin kempa panas ini secara umum dapat dilihat pada Gambar 2.

Dengan penggunaan sistem hidrolik sederhana berpenggerak pompa tangan (hand рuтр) di mana gaya tekan hidrolik yang dapat diberikan hanya searah, maka gaya tekan hidrolik pada mesin ini bergerak dari bawah ke atas dengan panjang langkah (stroke) maksimum sebesar 160 mm. Sedangkan untuk kembali pada posisi awal, sistem hidrolik mengandalkan gaya berat/gravitasi yang berasal dari pelat bawah yang ditopang oleh silinder hidrolik. Pilihan desain seperti ini dipilih agar dapat menyederhanakan konstruksi mesin, agar tidak perlu menggunakan elemen gaya tambahan untuk mengembalikan posisi pelat ke posisi awal.

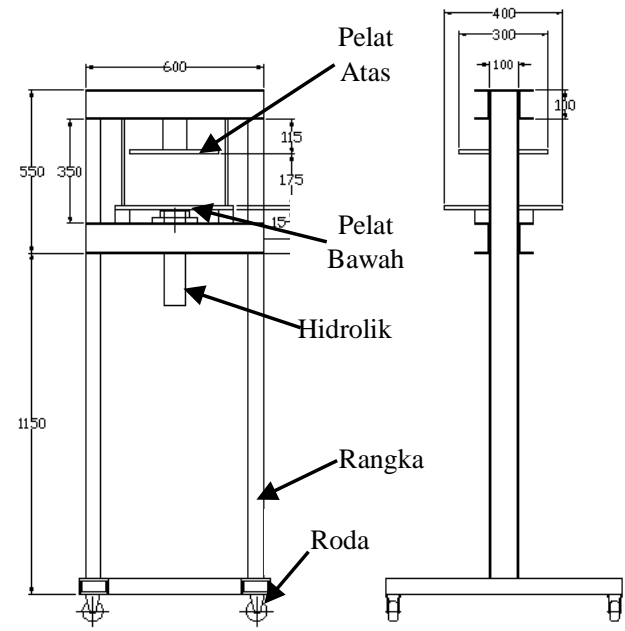

Gambar 2. Desain mesin kempa panas
Sedangkan desain konstruksi pelat kempa panas seperti pada Gambar 3 merupakan dua buah pelat di mana pelat atas bersifat statis yang ditumpu oleh besi kanal pada rangka dan pelat bawah bersifat dinamis yang ditumpu oleh hidrolik dan dapat bergerak dalam arah transversal.

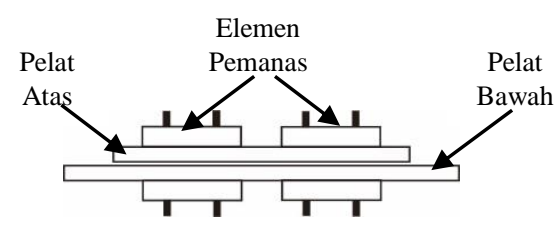

Gambar 3. Desain konstruksi pelat kempa panas

\section{Pembuatan dan Pemilihan Komponen}

Dari desain dan perancangan mesin kempa panas yang telah dibuat, maka dilakukan pembuatan dan pemilihan komponenkomponennya antara lain:

\section{Rangka atau Frame}

Rangka mesin dibuat dengan metoda semi knock down, yaitu dengan meminimalkan proses pengelasan pada penyambungan besi. Tujuan dari metoda ini yaitu untuk mempermudah dalam perakitan termasuk pemasangan sistem hidrolik dan pelat penekan. Rangka utama dibuat dengan dimensi $1700 \mathrm{~mm}$ x $600 \mathrm{~mm} \quad$ x $400 \mathrm{~mm}$ menggunakan besi kanal 7 .

\section{Pelat Pengepresan}

Pelat pengepresan merupakan komponen utama dari mesin ini. Pelat yang berbahan besi ini terdiri dari dua buah, yaitu pelat atas dan pelat bawah. Dimensi pelat atas berukuran $300 \mathrm{~mm} x$ $300 \mathrm{~mm} \times 15 \mathrm{~mm}$ dan pelat pemanas bawah berukuran $400 \mathrm{~mm}$ x $400 \mathrm{~mm}$ x $15 \mathrm{~mm}$.

\section{Elemen Pemanas dan Sistem Kendalinya}

Elemen pemanas yang digunakan pada mesin ini yaitu jenis pemanas tabung (tubular heater). Jumlah elemen pemanas yang digunakan sebanyak empat buah, sehingga daya total yang digunakan sebesar 4 × 600 watt $=2400$ watt. Elemen-elemen pemanas ini dilapisi oleh alumunium untuk meningkatkan luas permukaan kontak dengan pelat pengepresan sehingga perpindahan panas antar keduanya dapat berlangsung lebih baik. Pelapisan elemen pemanas oleh alumunium ini menggunakan proses pengecoran dengan ukuran lapisan $100 \mathrm{~mm}$ x 260 $\mathrm{mm}$ x $20 \mathrm{~mm}$.

\section{Hidrolik}

Pemilihan sistem hidrolik didasarkan oleh tekanan minimal yang diperlukan dalam pembuatan komposit pada penelitian ini. Di 
samping itu sistem hidrolik ini juga harus dapat mengakomodir variasi tekanan yang dibutuhkan dalam pembuatan komposit. Oleh karena itu pada kegiatan rancang bangun mesin kempa panas ini dipilih hidrolik dengan kapasitas 15 ton.

\section{Aksesoris}

Di samping komponen-komponen utama, terdapat juga aksesoris mesin yang dipasang seperti roda, meja kerja, cover, steker dan lain sebagainya. Aksesoris tersebut dirakit atau dipasang untuk menunjang fungsi dari mesin kempa panas.

\section{Pengujian Serat Limbah Pemintalan Kapas dan Komposit}

Pengujian serat limbah pemintalan kapas meliputi penentuan kadar kemurnian serat menggunakan Shirley Analyzer dengan standar SNI 08-1268:1989 dan penentuan karakteristik serat menggunakan alat uji HVI. Sedangkan pengujian komposit berupa kekuatan tarik dilakukan dengan pengujian beban putus dan mulur geotekstil dengan standar SNI 4417:2017.

\section{Uji Coba Tanpa Bahan Baku}

Uji coba mesin tanpa bahan baku diperlukan untuk mengetahui konstruksi, kemampuan pengepresan dan kemampuan pemanasan. Selain itu, dalam uji coba ini diamati apakah terdapat bagian mesin yang cacat atau kurang tepat penyetelannya (setting), sehingga dapat segera diketahui dan diperbaiki atau diganti. Uji coba ini dilakukan selama 5 x 8 jam disertai dengan proses kalibrasi temperatur terhadap fungsi pemanas.

\section{Uji Coba dengan Bahan Baku}

Uji coba dengan bahan baku dilakukan untuk mengetahui unjuk kerja mesin pada saat memproses bahan baku berbentuk lembaran nirtenun. Pada ujicoba ini diamati setingan hidrolik terhadap pelat penekan dan kondisi bahan baku dalam setiap tahapan proses. Uji coba dengan bahan baku ini dilakukan dengan menggunakan nirtenun dari serat limbah pemintalan kapas dan polyester low melt dengan komposisi $80 \%$ dan $20 \%$. Durasi proses tekan-panas dicari untuk mendapatkan waktu yang tersingkat dengan ikatan antar serat yang dibentuk dari melelehnya polyester low melt dapat berlangsung dengan baik.

\section{HASIL DAN PEMBAHASAN}

\section{Kemurnian dan Karakteristik Bahan Baku Limbah Pemintalan Serat Kapas}

Hasil pengujian terhadap serat limbah pemintalan kapas yang telah diolah dapat dilihat pada Tabel 1. Bahan ini diperoleh sebagian besar berasal dari proses blowing pada pemintalan kapas. Berdasarkan pengamatan visual dan stapling, bahan ini masih memiliki serat yang cukup panjang. Kemudian dilakukan pengujian kadar kemurnian serat (lint content) menghasilkan data lint content sebesar $21 \%$; trash yang mengandung serat sebesar $60 \%$, serta debu dan lain-lain sebesar $19 \%$. Sedangkan hasil pengujian karakteristik serat limbah pemintalan kapas hasil pengolahan dapat dilihat pada Tabel 1.

Tabel 1. Karakteristik serat limbah pemintalan kapas hasil pengolahan

\begin{tabular}{ll}
\hline \multicolumn{1}{c}{ Parameter } & \multicolumn{1}{c}{ Nilai } \\
\hline Kehalusan & 2,22 micronaire \\
Panjang Serat & 0,93 inchi \\
Kerataan Panjang & Unf 51,9 \\
Indeks Serat Pendek & 35,2 \\
Kekuatan & $28,5 \mathrm{gr} / \mathrm{Tex}$ \\
Mulur & $12,8 \%$ \\
\hline
\end{tabular}

Serat kapas hasil pengolahan dari limbah pemintalan ini memiliki karakteristik mutu yang masih masih dapat dipintal menjadi benang ${ }^{3}$.

\section{Prototipe Mesin Kempa Panas}

Hasil kegiatan ini berupa prototipe mesin kempa panas seperti pada Gambar 4. Prototipe mesin ini digunakan untuk peningkatan kualitas komposit yang terbuat dari serat limbah pemintalan kapas sebagai penguat dan polyester low melt sebagai matriks. Pembahasan pada tulisan ini hanya mencakup penggunaan prototipe mesin ini pada bahan tersebut.

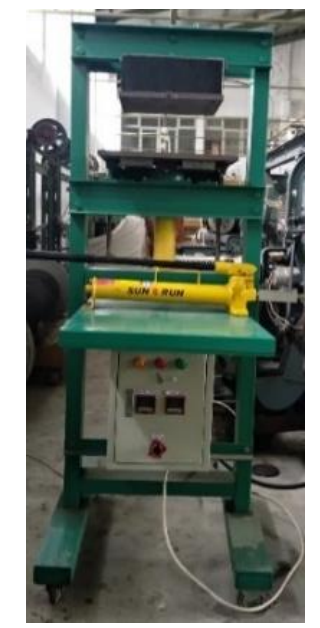

Gambar 4. Prototipe Mesin Kempa Panas

Di samping komposit berbahan dasar serat limbah pemintalan kapas, mesin ini juga telah digunakan untuk pembuatan komposit dengan bahan dasar serat lainnya seperti serat daun nanas, serat biduri, serat rami, dan serat ijuk dengan menggunakan matriks polyester low melt. Adapun spesifikasi prototipe mesin kempa panas hasil pengembangan ini dapat dilihat pada Tabel 2. 
Tabel 2. Spesifikasi Prototipe Mesin Kempa Panas

\begin{tabular}{ll}
\hline \multicolumn{1}{c}{ Aspek } & \multicolumn{1}{c}{ Keterangan } \\
\hline Bahan Rangka & Besi Kanal 7 \\
Dimensi & $1700 \times 600 \times 400 \mathrm{~mm}$ \\
Perakitan & Semi Knockdown \\
Tipe Pengepres & Oil Hydraulic Press \\
Kapasitas Pengepres & 15 Ton \\
Tipe Pemanas & Tubular Heater \\
Daya Pemanas Total & 2.400 Watt \\
Temperatur Maksimum & $200^{\circ} \mathrm{C}$ \\
Ukuran Komposit & $30 \times 30 \mathrm{~cm}$ \\
\hline
\end{tabular}

\section{Hasil Uji Coba}

Melalui uji coba tanpa bahan baku dapat diperoleh informasi hasil pengamatan mesin pada kemampuan pengepresan atau penekanan. Melalui hidrolik, pelat bawah bergerak ke atas untuk melakukan pengepresan pada pelat atas. Tekanan maksimal yang dapat dilakukan adalah sebesar 11 $\mathrm{kg} / \mathrm{cm}^{2}$. Pada saat tekanan maksimal ini, tidak terlihat adanya lenturan (bending) pada pelat atas, pelat bawah, kedua tumpuan, maupun rangka. Sedangkan gerakan turun pelat bawah menggunakan gaya berat atau gravitasi dari pelat bawah tersebut sebesar $\pm 19 \mathrm{~kg}$.

Sedangkan panas pada bagian pelat penekan, telah terinsulasi cukup baik terhadap bagian rangka dengan penggunaan ebonit dan kayu sebagai insulator sehingga rambatan panas pada rangka relatif kecil. Kemampuan pemanasan diamati dengan mengukur kemampuan temperatur maksimal dan waktu yang dibutuhkan untuk mencapai temperatur tertentu ${ }^{18}$. Data ujicoba ini dapat dilihat pada Tabel 3 .

Tabel 3. Data temperatur dan waktu pencapaian

\begin{tabular}{ccc}
\hline $\begin{array}{c}\text { Temperatur } \\
\left({ }^{\circ} \mathrm{C}\right)\end{array}$ & \multicolumn{2}{c}{ Waktu Pencapaian } \\
\cline { 2 - 3 } & $\begin{array}{c}\text { Pelat Atas } \\
(\text { Menit })\end{array}$ & $\begin{array}{c}\text { Pelat Bawah } \\
\text { (Menit) }\end{array}$ \\
\hline 50 & 5 & 6 \\
75 & 9 & 13 \\
100 & 14 & 19 \\
125 & 19 & 27 \\
150 & 25 & 37 \\
175 & 32 & 51 \\
200 & 43 & 85 \\
\hline
\end{tabular}

Hasil pengujian terhadap kemampuan pemanasan didapatkan nilai temperatur maksimal untuk mesin kempa panas ini sebesar $200^{\circ} \mathrm{C}$. Temperatur maksimal ini didasarkan pada temperatur maksimal yang dapat dicapai oleh pelat bawah. Sedangkan untuk pelat atas, temperatur maksimal yang dapat dicapai lebih dari $200^{\circ} \mathrm{C}$. Sedangkan waktu yang dibutuhkan untuk mencapai temperatur $200^{\circ} \mathrm{C}$ adalah sekitar 43 menit untuk pelat atas dan 85 menit untuk pelat bawah. Perbedaan ini disebabkan oleh berbedanya dimensi atau massa kedua pelat tersebut sehingga menyebabkan perbedaan laju perpindahan panas yang masuk dan keluar dari kedua pelat tersebut ${ }^{15}$.

Sedangkan hasil kalibrasi temperatur terhadap pelat atas dan pelat bawah pada mesin kempa panas didapatkan nilai koreksi sekitar 5 $10 \%$ bervariasi mengikuti kenaikan temperatur seperti terlihat pada Gambar 5. Nilai koreksi ini terkait dengan sistem kendali pemanasan dan panas yang hilang pada kedua pelat. Pada sistem kendali pemanasan, sensor temperatur yang digunakan hanya satu buah untuk tiap pelat dan posisinya berada pada tepi atau sisi pelat sedangkan elemen pemanas terletak pada bagian tengah pelat. Posisi tepi pelat memiliki laju perpindahan panas yang lebih tinggi karena memiliki luas permukaan kontak yang lebih besar dengan udara sekeliling. Hal ini yang menyebabkan adanya selisih pembacaan temperatur antara standar dengan sensor.

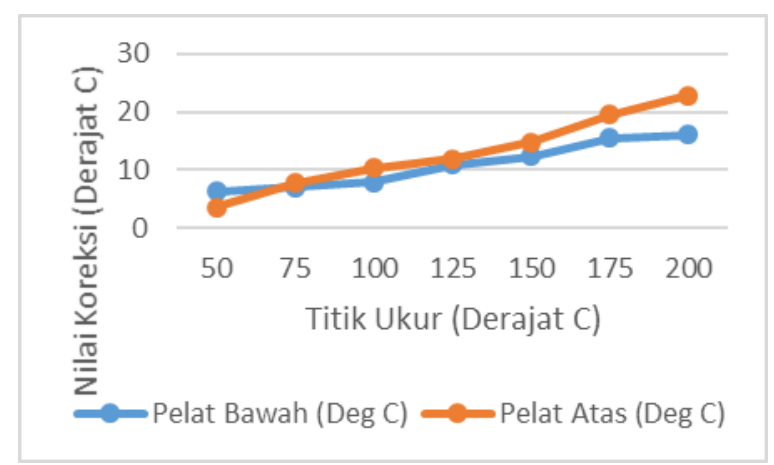

Gambar 5. Nilai koreksi temperatur

Pada pelat bawah, nilai koreksi temperatur sampai dengan $100^{\circ} \mathrm{C}$ rata-rata sekitar $7^{\circ} \mathrm{C}$. Pada temperatur antara $100^{\circ} \mathrm{C}$ sampai dengan $150^{\circ} \mathrm{C}$, rata-rata nilai koreksi sebesar $12^{\circ} \mathrm{C}$. Pada temperatur antara $150^{\circ} \mathrm{C}$ sampai dengan $200^{\circ} \mathrm{C}$ rata-rata nilai koreksi sebesar $16^{\circ} \mathrm{C}$. Sedangkan pada pelat atas, nilai koreksi temperatur sampai dengan $100^{\circ} \mathrm{C}$ rata-rata sekitar $7^{\circ} \mathrm{C}$. Pada temperatur antara $100^{\circ} \mathrm{C}$ sampai dengan $150^{\circ} \mathrm{C}$, rata-rata nilai koreksi sebesar $13^{\circ} \mathrm{C}$. Pada temperatur antara $150^{\circ} \mathrm{C}$ sampai dengan $200^{\circ} \mathrm{C}$ rata-rata nilai koreksi sebesar $21^{\circ} \mathrm{C}$. Semakin tinggi temperatur kerja atau temperatur titik ukur, nilai koreksi semakin tinggi. Hal ini disebabkan oleh semakin tingginya perbedaan temperatur pelat dengan temperatur lingkungan sekitar atau $\Delta \mathrm{T}$ yang proposional dengan laju perpindahan panas, sehingga menyebabkan semakin besarnya nilai koreksi. Sementara itu nilai koreksi pada pelat atas sedikit lebih besar dibandingkan pelat bawah. Hal ini disebabkan oleh konstruksi mesin kempa panas, di mana tumpuan pelat atas pada rangka menyebabkan masih adanya perpindahan panas secara konduksi yang lebih besar dibandingkan yang terjadi pada pelat bawah. 
Sedangkan untuk hasil uji coba mesin dengan menggunakan bahan baku, saat temperatur kedua pelat telah mencapai temperatur leleh polyester low melt sekitar $120^{\circ} \mathrm{C}$ waktu dibutuhkan untuk melelehkannya sekitar 20 detik. Untuk mempersingkat waktu pelelehan, maka temperatur yang digunakan dapat ditingkatkan agar laju perpindahan panas dari kedua pelat ke komposit semakin tinggi. Sampel komposit kemudian diuji beban putus dan mulur geotekstil dengan cara cekau (grab). ${ }^{17}$ Hasil pengujian beban putus terhadap komposit ini sebelum dan sesudah diprespanas diperlihatkan pada Gambar 6.

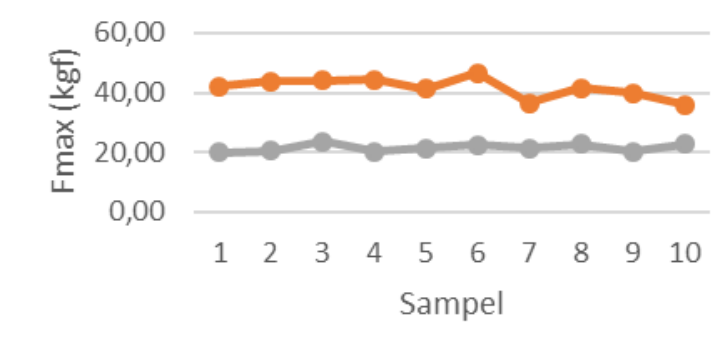

$\longrightarrow$ Dipres-panas $\quad \longrightarrow$ Tidak Dipres-panas

Gambar 6. Perbandingan kekuatan tarik

Kekuatan tarik mengalami perubahan disebabkan karena peningkatan kekuatan yang dapat dicapai melalui proses pres-panas. Rata-rata kenaikan kekuatan tarik dari sampel yang diuji sebesar 93,23\%. Proses pres-panas ini terdiri dari dua proses yaitu proses pengepresan dan proses pemanasan, di mana kedua proses tersebut secara simultan memberikan pengaruh terhadap peningkatan kekuatan komposit. Perbedaan komposit sebelum dan sesudah proses pres-panas ditunjukkan pada Gambar 7. Gambar yang diambil menggunakan kamera digital tersebut menunjukkan secara visual adanya perbedaan fisik berupa ikatan yang terjadi di antara komponenkomponen penyusun komposit.

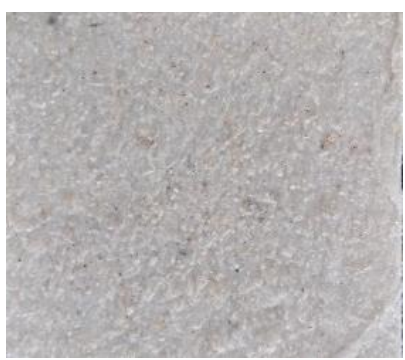

Sebelum

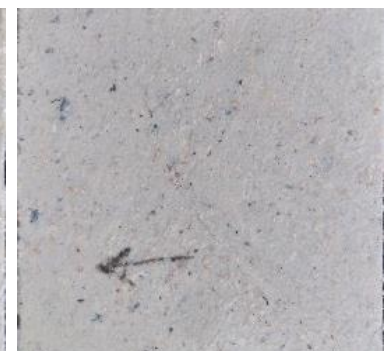

Sesudah
Gambar 7. Perbandingan sampel komposit sebelum dan sesudah proses prespanas

Meningkatnya kekuatan tarik yang dihasilkan melalui tekanan pengepresan terjadi karena adanya peningkatan interaksi di antara komponen-komponen penyusun komposit yaitu matriks dengan serat, matriks dengan matriks, serat dengan serat, serta peningkatan ikatan antar-muka (inter-facial bond) material penyusun sehingga mengurangi void yang terbentuk pada komposit. Ikatan antar muka yang meningkat akan menyebabkan ketahanan tarik komposit meningkat. Ikatan antar muka memungkinkan transfer tegangan tarik yang lebih baik di antara komponen pembentuk komposit, yang pada gilirannya meningkatkan kekuatan tarik komposit. ${ }^{14}$

Sementara itu kekuatan tarik juga mengalami peningkatan melalui pemberian panas oleh mesin kempa panas sehingga polyester low melt yang berfungsi sebagai matriks akan meleleh dan mampu menyelimuti serat-serat. Fenomena ini mulai terjadi pada temperatur sekitar $120^{\circ} \mathrm{C}$, di mana mulai terjadi ikatan antara matriks dengan serat maupun ikatan antara matriks dengan matriks sehingga membentuk mekanisme penguatan di dalam komposit. ${ }^{13}$

Proses pres-panas juga mempengaruhi kenaikan pada nilai kemuluran (elongation) dari komposit. Rata-rata kenaikan mulur dari sampel yang diuji sebesar $47,40 \%$ seperti dapat dilihat pada Gambar 8. Fenomena kenaikan mulur ini terjadi hampir sama dengan terjadinya kenaikan kekuatan tarik.

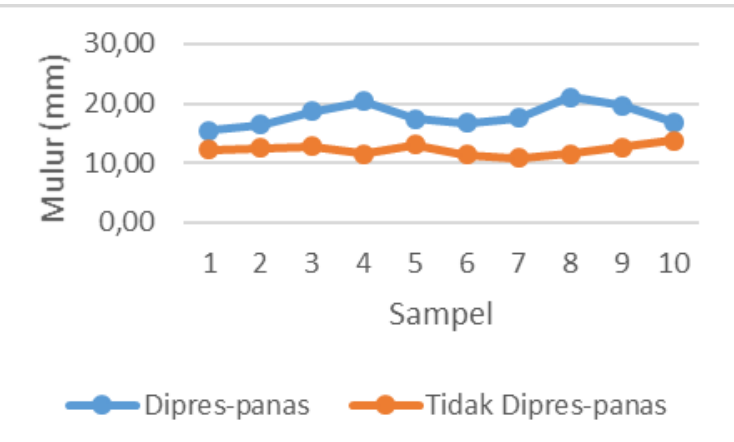

Gambar 8. Perbandingan kemuluran

Proses pres-panas menyebabkan naiknya kemuluran pada komposit melalui terbentuknya ikatan bidang antar-muka (inter-facial bond) antar matriks maupun antara serat dengan matriks secara lebih baik. Sebelum mengalami proses pres-panas, kedua bahan pada komposit yaitu serat dan matriks secara individu kurang memiliki kekuatan luluh bahkan cenderung bersifat getas. Setelah komposit mengalami proses pres-panas, pembebanan pada komposit akan menyebabkan ikatan antar matriks maupun ikatan antar matriks dan serat secara bersamaan akan mengalami deformasi. Terbentuknya ikatan-ikatan inilah yang menyebabkan meningkatnya kemuluran dari komposit. ${ }^{13}$ 


\section{KESIMPULAN}

Pada penelitian ini dapat diambil

kesimpulan sebagai berikut:

- Mesin kempa panas hasil rekayasa tersebut dapat digunakan dengan maksimal sampai dengan temperatur $200^{\circ} \mathrm{C}$ dengan gaya tekan $11 \mathrm{~kg} / \mathrm{cm}^{2}$.

- Proses pembuatan komposit dari campuran polyester low melt sebagai matriks dan serat limbah pemintalan kapas merupakan proses yang bertahap dan mesin kempa panas ini digunakan untuk membantu proses pengikatan serat-serat tersebut oleh polyester low melt.

- Sifat mekanik dari komposit 80\% limbah kapas dan $20 \%$ polyester low melt yang dihasilkan sebelum dipres-panas kekuatan tarik rata-rata sebesar 21,54 kgf, kemuluran rata-rata sebesar $12,23 \mathrm{~mm}$, dan setelah dipres-panas pada temperatur $140{ }^{\circ} \mathrm{C}$, tekanan $=100$ bar, dan waktu $=20$ detik, kekuatan tarik rata-rata menjadi 41,62 kgf, kemuluran rata-rata menjadi $18,03 \mathrm{~mm}$. Melalui proses pengepresan dan pemanasan ini didapatkan kenaikan kekuatan tarik sebesar 93,23\% dan kemuluran sebesar $47,40 \%$.

\section{PUSTAKA}

1. Rusim \& Mardjono. Biologi Tanaman Kapas. Monograf Balittas.7. (2001).

2. Aththorick, T. A. Evolusi Genetika Kapas. Medan. USU Digital Library.(2003).

3. Istinharoh. Pengantar Ilmu Tekstil 1. Jakarta : Direktorat Pembinaan SMK. (2013).

4. Hull, D. \& Clyne, T.W. An Introduction to Composite Materials. Cambridge: Cambridge University Press. (2012).

5. Ashby, M. F. \& Jones, D. R. H. Engineering Materials: An Introduction to their Properties and Applications Cambridge: International Series on Materials Science and Technology. (1982).

6. ASM International Handbook : Composites. (ASM Handbook.Vol 21. 2001).

7. Jones, R. M. Mechanics of Composite Material. Virginia: Taylor \& Francis. (1999).

8. Callister, W.J. Materials Science And Engineering An Introduction 8th Edition. New
Jersey: John Wiley \& Sons Inc Hoboken. (2009).

9. Masturi, Mikrajuddin, Khairuurijal. Efektivitas Polyvinyl Acetate (PVAc) sebagai Matriks pada Komposit Sampah. ITB. 13(2). (2010).

10. Ghurri, A. Dasar-Dasar Mekanika Fluida. Bukit Jimbaran: Jurusan Teknik Mesin Universitas Udayana. (2014).

11. S. Yulianto, dkk. Pengaruh Beban terhadap Tekanan Pompa Hidrolik pada Reach Stacker Saat Proses Lifting Peti Kemas. Sintek 8(1). (2014).

12. Hariyanto, A. Pengaruh Siklus Thermal pada Rekayasa Bahan Komposit Sandwich Berpenguat Serat Rami dengan Core Sekam Padi untuk Panel Otomotif. Simposium Nasional RAPI XIII. Surakarta : FT UMS. (2014).

13. Kurniawan, I. P., Wisnu Raharjo, W., \& Triyono, T. Pengaruh Variasi Temperatur Kempa panas terhadap Kekuatan Bending Komposit rHDPE Cantula. Prosiding SNST ke7. Semarang: FT Universitas Wahid Hasyim. (2016).

14. Ratmanto, R., Wisnu Raharjo, W., \& Triyono, T. Pengaruh Tekanan Pengepresan terhadap Kekuatan Bending Komposit rHDPE Cantula. Prosiding SNST ke-7. Semarang : FT Universitas Wahid Hasyim. (2016).

15. Satriya, D. A. Perancangan Sistem Pemanas pada Rancang Bangun Mesin Pengaduk Bahan Baku Sabun Mandi Cair, JRM. 01(02). (2014).

16. Teguh B. P., dkk. Purwarupa Sistem Kendali Suhu dengan Pengendali PID pada Sistem Pemanas dalam Proses Refluks/Distilasi. IJEIS 3(1). (2013).

17. SNI 4417-2017 : Metode Uji Beban Putus dan Mulur Geotekstil dengan Cara Cekau (Grab). Badan Standardisasi Nasional. (2017).

18. Junaidi, Bukhari, \& Nofriadi. Rekayasa Alat Kempa Panas (Hot Press) Sistem Penekanan Dongkrak Hidrolik untuk Pembuatan Papan Komposit. Jurnal Teknik Mesin. 8(1). (2011).

19. Polyester Low Melt Fiber. Available at https://petersenoverseas.com/polyester-lowmelt-fiber/ (Accessed : $21^{\text {st }}$ May 2019). 